International Journal of Engineering \& Technology, $7(3.29)(2018) 199-202$
SPC
International Journal of Engineering \& Technology
Website $: \frac{w w . s c i e n c e p u b c o . c o m / i n d e x . p h p / I J E T}{2}$
Research paper

\title{
Survey on multi-channel schemes in wireless body area network
}

\author{
M. Raj Kumar Naik ${ }^{1}$, P. Samundiswary ${ }^{1}$ \\ ${ }^{1}$ Dept. of Elect. Engg, Pondicherry central university, Pondicherry, India \\ *Corresponding author E-mail: raj.meghavath@gmail.com
}

\begin{abstract}
The evolution and empowerment of Wireless Body Area Network (WBAN) is achieved through the rapid advancement in the wireless communication technologies. The use of different kinds of sensors which are utilized in the health care applications for patient monitoring are helped for diagnosis of life threatening disease which can be improved by using WBAN. These wearable systems help in controlling the life of patient is as they play essential role to save patient's life. In recent past, the system architecture is constructed for WBAN for monitoring of health care application and enhancing the technical requirements in a WBAN network. Although, Wireless Body Area Networks (WBAN) is one of the emanate technology which utilizes the patient health condition for monitoring in real time, several issues that are faced by WBAN are Quality of Service (QoS), security, data loss, authentication, channel issues and energy efficiency. Most of the WBANs utilizes wireless channel for process of communication in which these typical sensors with single transceiver device transmits the information with low power by utilizing a single channel using Medium Access Control (MAC) layer in WBAN. However, the degradation in performance of these devices is high when the sensors density is increased. The solution to overcome this performance degradation is carried out by making use of multiple channels, due to which the channels are optimally utilized and the cooperation among the sensor nodes is achieved. In this paper, the survey of different protocols used for WBAN under different channel conditions is discussed in WBANs with its merits.
\end{abstract}

Keywords: WBAN; QOS; MAC; BSN; EMRS; DES.

\section{Introduction}

Wireless Body Area Network (WBAN) is one of the wireless networks which is used on, in or around the human body for communication using different nodes of sensor to monitor key movements of patient's and essential parameters of body[1]. A wireless biomedical sensor helps in measuring physiological signals from the body as the data acquired is very important and crucial information which is obtained through essential deployments of WBAN. The sensor node which is used for data acquisition called sink node will help in gathering all the signals information which is obtained during monitoring process by an individual device, e.g. smart phone or a PDA. Then the obtained information of the patient's health will be monitored by sink node and it is then transmitted to the healthcare professional. Hence, Wireless Body Area Network (WBAN) helps in designing and developing a unique network which is used for monitoring and guiding crucial signs like ElectroCardio Gram (ECG), temperature, blood pressure etc. A broad scope of unique applications of WBAN is in the fields of Emergency Medical Response System (EMRS), Ubiquitous Health Monitoring (UHM) and also living healthy styling are promoted [2]. However, in the service of health care system to depend on the workforces who are specialized is greatly reduced and makes people free by avoiding frequent visit to hospitals by using UHM service in WBAN. Each network in WBAN is carried out by a Single application as the support for mobility is less and storage capacity is scarce. So, the countries where infrastructure in the medical field and the people who are associated to it will face a serious challenge to build a health-care systems with recommendable cost - effective and better service. In addition, the lives of innumerable people are saved by using minimum human efforts in the disaster prone region in which vital signs of the patients who are injured can be monitored and it is reported to remote hospitals for the people safety which is carried out by the rapid deployment of Emergency Medical Response System which is develop by use of temporary WBAN.

Generally, the communication in WBAN network is done through the wearable devices between computers-humans. These WBAN wearable devices are used for the exact signal sensing from the body after that a low level processed signal sensor will be forwarded and then finally obtained signal is transmitted wirelessly to a unit of local processing in the network. Although, some of its serious issues such as privacy, Quality of Service (QOS), efficiency of energy and channel issues are faced due to the distinctive properties in WBAN. In order to overcome these issues an architecture of Wireless Body Area Network using a three-tier Network is given in Fig.1. 


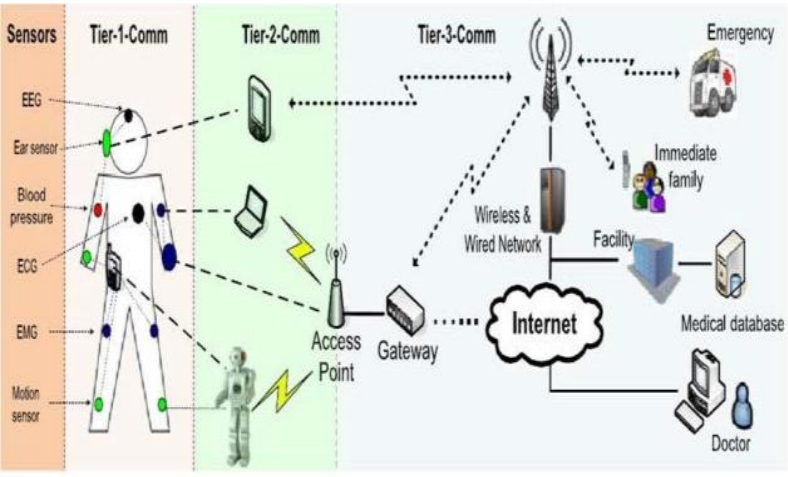

Fig. 1: Three-Tier Wireless Body Area Sensor Network Architecture.

WBANs have stringent requirements and their characteristics are different from the networks of other kinds like wireless mesh networks, ad-hoc networks and wireless sensor networks. A star topology is implemented for the standard WBAN which uses single channel based on contention. However, with the use of one radio transceiver [3] channel, it will have high data latency and energy inefficiency because the data from all nodes is received by the sink node simultaneously in the network. As a result, the co-channel interference in a multi-hop environment is more and capacity is reduced by using single-radio in a multi-hop environment [4]. TABLE 1 illustrates specifications of WBAN.

Table 1: WBAN Specification

\begin{tabular}{ll}
\hline Factors & WBAN \\
\hline IEEE Standard & 802.15 .6 \\
Size of Node & Small is essential \\
Nodes Density & $<64$ \\
Range & $2 \mathrm{~m}-5 \mathrm{~m}$ \\
Power & $30 \mathrm{mw}$ \\
Type & Heterogeneous \\
Rate & 1 Kbps-10Mbps \\
Technology & Requires Low power wireless technology
\end{tabular}

In this paper, multichannel schemes of WBAN are discussed to avoid channel collisions and interference in the links when same channel is used. From the survey, it is inferred that, a dual channel can help to improve the connectivity and reliability of WBAN network. The rest of the paper is organized as follows: Section 2 deals with IEEE 802.16 MAC overview. Communication Channel and Routing is given in section [3]. Section [4] deals with Multichannel AODV Routing protocol. Finally the conclusion is drawn in section 5.

\section{IEEE 802.15.6 mac overview}

The growing demands for short range, wireless communication in or around a human body but not restricted to only humans, is developed by IEEE 802.15.6 standard in order to globally accommodate and accelerate the expanded applications of WBAN. The Body Area Networks (BANs) standard divides the networks into sets and each of its sets is projected to have multiple nodes with one Body Network Coordinator (BNC). The operation of a BNC is carried out by following ways such as non-beaconed mode with super-frame or non-beaconed mode without super-frame, a beaconed mode with super-frame. The synchronization between all BAN nodes and BNC is accessible only when the first mode of network shows extra energy efficiency with high reliability. Although, when data is to be transmitted, nodes which are in the sleep mode will initiate intermittently. Therefore, it is being generally used in medicinal applications. Fig. 2 depicts that the beacon method is having seven access phases for superframe structure such as Contention Access Phase (CAP), Exclusive Access Phases (EAP), Random Access Phases (RAP) and Managed Access Phases (MAP) [5]. In the beginning of each super frame, beacon will be communicated with BNC to define another elective beacon formerly to start the CAP and size of each contact phase. For the beginning of communication by using CSMA/CA or S-ALOHA access scheme, the admittance stages EAP 1, EAP 2, RAP 1, RAP 2, and CAP will be used for resisted distribution by nodes. EAP is usually used only by utmost data, User Priorities (UP's), and for emergency and medical incident report.

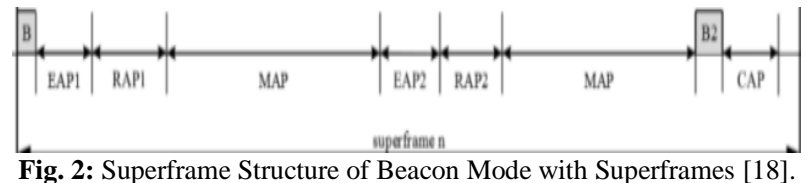

\section{Communication channel and routing}

Wireless communications helps in communicating the physiological parameters which are obtained from the human body through the sensor or actuator which are connected through miniaturized devices by using Wireless Body Area (WBAN) technology and the obtained data is transmitted to end user in the network.A single wireless band is used by WBANs that is utilized for communication of wireless narrowband (including Medical Implant Communications systems (MICS) and Industrial Scientific and Medical band (ISM)), UWB wireless band or Human Body Communications (HBC) band. However, due to the advancement in multi-channel communication in WBANs will helps in improvement of performance, connectivity and robustness by developing key enabled technology like architecture of radio system, antennas and data transfer link using simple protocols.

So, a WBAN system model consists of number of sensors nodes in which every node can transmit the information to different channels at same time because it is armed with two radios which helps in transmitting and receiving the information [6],[7] when it is connected to two wireless channels. the dual-channel node structure will consists of module for communication, Manager of a Resource along with an Application module. The module of Application which is used for data monitoring will send data from source to BNC sink for the transmission of data for that application. The data transmission between nodes is supported by the communication module which consists of two radio modules, two MAC modules and one Routing Module.

Thus, a survey of WBANS routing protocols are specified by [8][9]. The analysis and discussions of different routing metrics have been given in [10] which cover the constraints of routing like path length, network delay, bandwidth, reliability, load balancing, energy, communication cost and many more. In order to choose a shortest path, a hop count metric is used extensively for the existing protocols like AODV [11], Dynamic Source Routing (DSR) [12], and Destination-Sequenced Distance-Vector (DSDV) [13]. It creates least overhead to route the packets and do not entail any learning procedure to obtain linked quality evidence which can be used in hop count process. However, the other factors which are not considered are transmission rate, interference, packet loss ratio, and link quality. Due to which some network surrounds the hop count and results in poor performance. Hence, the transmission power may be increased by preferring few long hops over numerous shorter hops as the hop count metric by the nodes. The channel diversity is improved by the Weighted Cumulative Expected Transmission Time (WCETT) metric which is developed for multichannel networks. It depends on Expected Transmissions (ETX) and Expected Transmission Time (ETT) metrics where ETX metric [14] is well-defined as the expected number of transmission efforts requisite to bring a packet effectively over the link whereas ETT [15][16] is basically a ETX which is accustomed to provide the expected time to transfer a data packet.

\section{Multichannel schemes of WBAN}

WBAN devices are generally miniature low powered which are designed to operate with Single transceiver devices with single control 
channel and multiple data channels. So, the data from the channel is transmitted or received whenever a data channel is turned on but the current unused channel which are present in the network can not be known to the node which is under use during that time. As a result, MAC and multi-channel routing protocols are required by a
Body Network Controller (BNC) in a WBAN network for supporting multichannel communication in the network. TABLE II illustrates different protocols used in Wireless Body Area Network.

Table 2: Different Protocols used in WBAN

\begin{tabular}{|c|c|c|c|c|}
\hline Authors name & Protocol & $\begin{array}{l}\text { Simulation } \\
\text { platform }\end{array}$ & Inference & Advantage \\
\hline $\begin{array}{l}\text { Beibei, } \\
\text { Changle [17] }\end{array}$ & EDMAC & $\begin{array}{l}\text { Eclipse plat- } \\
\text { form }\end{array}$ & $\begin{array}{l}\text { Use of Traditional Carrier Sense Multiple Access with Collision Avoid- } \\
\text { ance (CSMA/CA) resulted in higher packet delay with more energy } \\
\text { consumption during overhearing process. Thus, to report this problem, } \\
\text { an Energy-Delay efficient Multi-channel MAC (EDMAC) protocol is } \\
\text { proposed which showed that ED MAC scheme significantly decreases } \\
\text { the packet delay and improves the throughput, energy efficiency, and } \\
\text { channel utilization. }\end{array}$ & $\begin{array}{l}\text { ED-MAC gives } \\
\text { higher throughput, } \\
\text { lower delay and } \\
\text { energy consump- } \\
\text { tion. }\end{array}$ \\
\hline $\begin{array}{l}\text { Benmansour, } \\
\text { Ahmed [18] }\end{array}$ & $\begin{array}{l}\text { an adapted } \\
\text { Low Latency } \\
\text { Queuing } \\
\text { (LLQ) } \\
\text { scheme in or- } \\
\text { der to improve } \\
\text { the QoS }\end{array}$ & $\begin{array}{l}\text { Over Castalia } \\
\text { simulator } \\
\text { based on OM- } \\
\text { NeT++ }\end{array}$ & $\begin{array}{l}\text { The different queuing strategies using in MAC layer results in packets } \\
\text { breakdown and the queuing mechanism over the IEEE } 802.15 .6 \text { has a } \\
\text { big influence on the network's performances. An adapted Low Latency } \\
\text { Queuing (LLQ) scheme is carried out to improve QoS. The simulation } \\
\text { results show that packets delivery rate, latency and energy consumption } \\
\text { is improved by using queuing scheme than the standard. }\end{array}$ & $\begin{array}{l}\text { The use of the } \\
\text { IEEE } 802.15 .6 \text { with } \\
\text { LLQ guarantee } \\
\text { timely services for } \\
\text { emergency packets. }\end{array}$ \\
\hline $\begin{array}{l}\text { Rongrong, } \\
\text { Hassine [19] }\end{array}$ & $\begin{array}{l}\text { Multi Channel } \\
\text { Broad- } \\
\text { cast(MCB) } \\
\text { protocol }\end{array}$ & $\begin{array}{l}\text { MCB for } \\
\text { application sce- } \\
\text { narios }\end{array}$ & $\begin{array}{l}\text { A robust multichannel wake-up schedule with minimum worst-case } \\
\text { broadcast delay is designed. It is carried out by designing Multi Channel } \\
\text { Broadcast protocol (MCB) and lower-bound. The lower-bound first de- } \\
\text { rives a worst-case broadcast delay with full diversity of any broadcast } \\
\text { protocol and a MCB is designed to satisfy the performance requirement } \\
\text { for the diversity and latency. }\end{array}$ & $\begin{array}{l}\text { MCB is used for } \\
\text { several typical ap- } \\
\text { plication scenarios }\end{array}$ \\
\hline $\begin{array}{l}\text { Stepan, } \\
\text { Dmitri [20] }\end{array}$ & $\begin{array}{l}\text { Extended for } \\
\text { cross-layered } \\
\text { gradient based } \\
\text { routing process }\end{array}$ & $\begin{array}{l}\text { Java based } \\
\text { event driven } \\
\text { simulator }\end{array}$ & $\begin{array}{l}\text { The multi-hop transmission that supports cooperative WBAN is carried } \\
\text { out by involving the cooperation of WBAN nodes and environmental } \\
\text { sensors. Simulations showed that there is improved performance in } \\
\text { terms of delay, packet loss and power consumption in comparison to co- } \\
\text { operative multi-channel MAC and routing solutions }\end{array}$ & $\begin{array}{l}\text { Improvements in } \\
\text { performance com- } \\
\text { pared to other co- } \\
\text { operative } \\
\text { MAC layer and } \\
\text { routing solutions }\end{array}$ \\
\hline $\begin{array}{l}\text { Omer, Zhang } \\
\text { [7] }\end{array}$ & $\begin{array}{l}\text { Extension } \\
\text { AODV Rout- } \\
\text { ing }\end{array}$ & $\begin{array}{l}\text { Single-band } \\
\text { Castalia model } \\
\text { built on OM- } \\
\text { NET++ }\end{array}$ & $\begin{array}{l}\text { A multi-channel extension to the Ad Hoc on Demand Distance Vector } \\
\text { (AODV) routing protocol is developed in which Received Signal } \\
\text { Strength Indication (RSSI), Link Quality Indicator (LQI) values are } \\
\text { used for selection of channel to transmit. Multi-channel AODV protocol } \\
\text { with RSSI and LQI channel resulted in better packet delivery than sin- } \\
\text { gle channel AODV but to obtain better routing stability, less AODV } \\
\text { control messages should be sent. }\end{array}$ & $\begin{array}{l}\text { Better routing sta- } \\
\text { bility and energy } \\
\text { efficiency com- } \\
\text { pared to single } \\
\text { channel }\end{array}$ \\
\hline $\begin{array}{l}\text { Sobia, Rein } \\
{[21]}\end{array}$ & $\begin{array}{l}\text { Dual-channel } \\
\text { AODV routing } \\
\text { protocol with } \\
\text { WMHC metric }\end{array}$ & $\begin{array}{l}\text { Castalia simu- } \\
\text { lator that is } \\
\text { built on the } \\
\text { OMTeT++ } \\
\text { platform }\end{array}$ & $\begin{array}{l}\text { The usage of dual bands can enhance throughput, reliability and connec- } \\
\text { tivity. As a result, a metric called Weighed Multichannel Hop Count } \\
\text { (WMHC) is taken to provide reduced interference and better channel di- } \\
\text { versity for inclusion in the multi-channel extension to the Ad Hoc on } \\
\text { Demand Distance Vector (AODV) routing protocol for use in WBANs. } \\
\text { The throughput improvement and interference reduction is obtained by } \\
\text { using WMHC method. }\end{array}$ & $\begin{array}{l}\text { Interference is re- } \\
\text { duced and through- } \\
\text { put is improved by } \\
\text { WMHC method. }\end{array}$ \\
\hline
\end{tabular}

\section{Conclusion}

The healthcare experience of people changes revolutionarily by an emerging and promising technology of WBAN. The important factors in WBAN such as deployment of sensor, density of sensors, energy efficiency, scalability, security and channel issues are some of the challenges that should be taken into consideration. In this paper, Wireless Body Area Network general outlook is given. Further, focus is made in respect of multi channel schemes carried out by this network. Extensive researches emphasised on single channel in WBAN using Medium Access Control (MAC) protocol which results in energy inefficiency, channel collision and inevitable interference. However, larger delay of packets and more consumption of energy for overhearing are the drawbacks of single channel obtained by using traditional Carrier Sense Multiple Access with Collision Avoidance (CSMA/CA) which cannot meet the request of medical data communication. Thus, the multi channel issues along with different protocols are taken into consideration for the resource saving. This survey will inspire to design and build a unique, reliable and dependable protocol under different channel conditions for WBAN.

\section{References}

[1] Movassaghi Shamaneh, Mehran Abolhasan, Justin Lipman, David Smith, Abbas Jamal pour," Wireless Body Area Networks: A Survey”, ,IEEE Communication Survey, Vol. 16, No. 3, pp.1658-1686, Aug-2014.

[2] Sofia NajwaRamli, RabiahAhmad, "Surveying the Wireless Body Area Network in the realm of Wireless Communication", in Proceedings of International Conference on Information Assurance and Security, Melaka, pp.58-61, Dec-2011.

[3] K. Cho, K Hee, Z.Jin and J.Cho University, Yongin, Korea, "Design and Implementation of a Single Radio MultiChannel MAC Protocol on IEEE 802.15.4 for WBAN", in Proceedings of International Conference on Ubiquitous Information Management and Communication, Cambodia, Jan-2014.

[4] R. Draves, J. Padhye, and B. Zill, "Routing in Multi-Radio, MultiHop Wireless Mesh Networks," in Proceedings of international conference on Mobile computing and networking, USA, pp. 114-128, , Oct-2004.

[5] A.Salam, A. Nadeem, K. Ahsan, M. Sarim, and K. Rizwan, "A class based QoS model for Wireless Body Area Sensor Networks", Research Journal of Recent Science, vol. 3, no. 7, pp. 69-78, May-2014.

[6] S. Omer, R. Vesilo, E. Dutkiewicz, Q. Zhang, "A dual channel routing protocol for wireless body area networks", in Proceedings of International Conference on Body Area Networks, Sydney, pp. 240246, Sep-2015 
[7] Sobia Omer, Rein Vesilo, Eryk Dutkiewicz and Qi Zhang, "An LQI Based Dual-channel Routing Protocol for Wireless Body Area Networks", in Proceedings of International Telecommunication Networks and Applications Conference, Sydney, pp. 320-325, Nov2015.

[8] L. Ma, M. Denko, "A routing metric for load-balancing in wireless mesh networks", in Proceedings of International Conference on Advanced Information Networking and Applications, Canada, pp. 409414, May-2007.

[9] S. Movassaghi and M. Abolhasan, "A review of routing protocols in wireless body area networks', Journal of Networks, Vol. 8, no. 3, pp. 559-575, 2013.

[10] J. I. Bangash, A. H. Abdullah, M. H. Anisi and A. W. Khan, "A survery of routing protocols in wireless body sensor networks", Sensors, pp.1322-1357, Jan-2014.

[11] Perkins, Charles, Elizabeth Belding-Royer, and Samir Das, "Ad hoc on-demand distance vector (AODV) routing", Network Working Group, Jul-2003.

[12] S. A. Ade1 and P.A.Tijare, "Performance Comparison of AODV, DSDV, OLSR and DSR Routing Protocols in Mobile Ad Hoc Networks", International Journal of Information Technology and Knowledge Management, Vol 2, No. 2, Dec-2010.

[13] Guoyou He, "Destination-Sequenced Distance Vector (DSDV) Protocol", Journal of parallel and distributed computing, Vol. 61, no. 7 , pp. $967-995,2001$

[14] D.S.J. De Couto, D. Aguayo, J. Bicket, and R. Morris. "A high throughput path metric for multi-hop wireless routing", Wireless Networks, Vol. 11, no. 4, pp. 419-434, 2005.

[15] S. Kim, O. Lee, S. Choi, and S.J. Lee, "Comparative analysis of link quality metrics and routing protocols for optimal route construction in wireless mesh networks", Ad Hoc Networks, Vol. 9, no. 7, pp. 1343-1358, 2011.

[16] P.M. Esposito, M.E.M. Campista, I.M. Moraes, L.H.M.K Costa,O.C.M.B. Duarte, and M.G. Rubinstein,"Implementing the expected transmission time metric for OLSR wireless mesh networks", Wireless Days, Dubai, pp. 1-5, Nov-2008.

[17] Beibei Zhang, Changle Li*, Zhe Liu, Xiaoming Yuan and Li Yang, "On Energy-delay Efficiency for WBAN: a Multi-channel Scheme", in Proceedings of International Conference on Communication Networks, China, Nov-2015.

[18] Tariq Benmansour, Toufik Ahmed, and Samira Moussaoui1, "Performance Analyses and Improvement of the IEEE.

[19] 802.15.6 CSMA/CA using the Low Latency queuing", Computer Aided Modeling and Design of Communication links and Networks, Sweden, June-2017.

[20] Rongrong Zhang, Hassine Moungla, Jihong Yu, Lin Chen, Ahmed Mehaoua and Lipade, " Multi-channel Broadcast in Asymmetric Duty Cycling Wireless Body Area Networks", in Proceedings of International Conference on Communication, France, May-2017.

[21] Stepan Ivanov, Dmitri Botvich, and Sasitharan Balasubramaniam, "Cooperative Wireless Sensor Environments Supporting Body Area Networks ", IEEE Transactions on Consumer Electronics, Vol. 58, No. 2, May 2012.

[22] Sobia Omer and Rein Vesilo, "A Channel Diversity Path metric for Dual Channel Wireless Body Area Networks ", in Proceedings of International Telecommunication Networks and Applications Conference, New Zealand, Dec-2016. 